\title{
Expansión clónica y caracterización genómica del proceso de integración del virus linfotrópico humano tipo I en la leucemia/linfoma de células T en adultos
}

\author{
Mercedes Salcedo-Cifuentes ${ }^{1}$, Jesús Cabrera',2, Yesid Cuesta-Astroz ${ }^{1}$, Edwin Carrascal ${ }^{3}$, \\ Yoshito Eizuru4, Martha C. Domínguez¹, Adalberto Sánchez', Felipe García-Vallejo ${ }^{1}$ \\ ${ }^{1}$ Laboratorio de Biología Molecular y Patogénesis, Departamento de Ciencias Fisiológicas, Facultad de \\ Salud, Universidad del Valle, Cali, Colombia \\ ${ }^{2}$ Facultad de Ciencias, Universidad de Nariño, Pasto, Colombia \\ ${ }^{3}$ Departamento de Patología, Facultad de Salud, Universidad del Valle, Cali, Colombia \\ ${ }^{4}$ Center for Chronic Viral Diseases, Faculty of Medicine, Kagoshima University, Kagoshima, Japan
}

Introducción. Aunque la integración del virus linfotrópico humano tipo I no es al azar, se desconocen muchos de los detalles de este proceso.

Objetivo. Evaluar las características de la cromatina celular adyacente a secuencias provirales en pacientes con leucemia/linfoma de células T en adultos asociada al virus.

Materiales y métodos. Se extrajo el ADN de biopsias de siete pacientes colombianos con leucemia/linfoma de células $\mathrm{T}$ en adultos y positivos para el virus linfotrópico humano tipo I. Éste se amplificó mediante reacción inversa en cadena de la polimerasa, para determinar el grado de expansión clónica y su composición de nucleótidos. A partir de 61 secuencias de ADN humano adyacentes a provirus, provenientes de pacientes leucémicos colombianos y japoneses, se efectuó un análisis in silico para obtener datos sobre su integración, las características de la cromatina y sus funciones asociadas.

Resultados. La expansión de clones celulares fue predominantemente oligoclónica. De las 61 secuencias de ADN adyacente a provirus, se seleccionaron 155 alineamientos que cumplieron con los criterios de inclusión (homologías $\geq 95 \%$, e-value $\leq 0,05$ ). De éstos, $74,84 \%$ fueron secuencias no codificantes repetidas y no repetidas. El 45,95\% de las integraciones provirales se localizó en los cromosomas de los grupos A y B. Se observaron tendencias de integración hacia exones de genes que se replican tempranamente, regulan el ciclo celular y participan en la transducción de señales.

Conclusiones. Los resultados permiten postular que la integración del virus linfotrópico humano tipo I se dirigiría hacia un ambiente genómico caracterizado por elevado contenido de C:G, genes de replicación temprana que regularían el ciclo celular y la transducción de señales.

Palabras clave: integración viral, virus linfotrópico de células T humanas tipo 1, leucemia/ linfoma de células T en adultos, reacción en cadena de la polimerasa, genoma humano, biología computacional.

Clonal expansion and genomic characterization of the human T-cell lymphotropic virus type I during the integration process in adult T-cell leukemia/lymphoma

Introduction. Although the integration of human T-cell lymphotropic virus type I into the T-cells is not a random process, the mechanistic details are not understood.

Objectives. The characteristics of the flanking host chromatin were evaluated at the integration sites in adult T-cell leukaemia/lymphoma (ATLL) patients infected with the virus.

Materials and methods. From seven leukemic Colombian patients positive for the human T-cell lymphotropic virus type I (HTLV-I), lymphocyte DNA samples were extracted and amplified by inverse polymerase chain reaction (IPCR). Clonal expansion and human genome nucleotide composition in an extension of $50 \mathrm{bp}$ was determined. To establish the characteristics of the human genome flanking provirus, 61 IPCR sequences from Colombian and Japanese ATLL patients, were analyzed in silico to obtain insights about the genomic structure, functions and nature of associated chromatin. 
Results. The clonal expansion of cell clones was predominantly oligoclonal. From 61 IPCR sequences, 155 alignments with homology higher than 95\% (e-value <0.05) were screened. Seventy-five percent of those sequences corresponded to non coding elements that include repetitive and non-repetitive DNA. Fifty percent of the proviral integrations were associated with chromosomes of A and B groups. Viral DNA integration tended to favor exons of genes that replicated early, controlled the cell cycle, or were involved in signal transduction.

Conclusions. The results indicated that HTLV-I integration was preferentially directed towards genomic environments with high $\mathrm{C}: \mathrm{G}$ content, and toward genes that replicate early, regulate cell cycle or involved with signal transduction.

Key words: Virus integration, human T-lymphotropic virus 1; leukaemia-lymphoma, adult T-cell; polymerase chain reaction; genome, human; computational biology.

El virus linfotrópico humano tipo I (HTLV-I) fue el primer retrovirus humano descubierto (1) y su infección es de distribución mundial. Los datos epidemiológicos recientes muestran que hay, aproximadamente, 25 millones de personas infectadas, con focos endémicos en Japón, el Caribe, algunas zonas de África Central, Centroamérica y Suramérica (2). En Colombia se registran seroprevalencias del $1 \%$ al $2 \%$, aunque en algunas zonas del Pacífico y de la región Caribe alcanzan valores de 7,5\% y $10 \%$, respectivamente (2-4).

La infección por este retrovirus se asocia con una amplia gama de manifestaciones clínicas que van desde infecciones asintomáticas hasta alteraciones linfoproliferativas y neurológicas (1). Entre éstas se incluye un tipo de cáncer poco común, conocido como leucemia/linfoma de células $T$ en adultos (5). Esta hemopatía maligna se caracteriza por una expansión de poblaciones de células T, cuyo fenotipo es CD3+, CD4+ y CD8-, CD25+, HLA-DR+ $(5,6)$.

A pesar del gran volumen de evidencias experimentales sobre la participación del virus en el proceso de transformación maligna de células $\mathrm{T}$, existen todavía preguntas sin contestar, principalmente en lo que respecta a los mecanismos celulares y moleculares que contribuirían a la génesis de la leucemia que

Correspondencia:

Felipe García-Vallejo, Laboratorio de Biología Molecular y Patogénesis, Departamento de Ciencias Fisiológicas, Facultad de Salud, Universidad del Valle, Calle 4b No.36-00, Edificio de Microbiología, oficina 226, Cali, Colombia.

Teléfono: (572) 518 5601; fax: (572) 5542468

labiomol@gmail.com

Recibido: 25/03/08; aceptado:11/12/08 se presenta después de un largo periodo de latencia de la infección viral.

En este sentido, los estudios recientes aportan datos de que el HTLV-I, en general, tiende a integrarse en regiones cromosómicas específicas, sensibles al tratamiento con ADNasa, asociadas con zonas de cromatina interfásica relajada (7), ricas en islas CpG (8-10), ubicadas en las bandas $R(11,12)$, y que contienen una alta densidad de genes (13). Se postula que, como resultado de la interacción de las características genómicas del huésped $(7,14,15)$ y de factores virales (16), se seleccionarían ambientes genómicos específicos para la integración, en donde cambios genéticos y epigenéticos contribuirían en el desarrollo de la leucemia (17).

Como otros virus, el HTLV-I tiene un gran potencial para dirigir la maquinaria de transcripción celular hacia su replicación y la producción de su progenie viral (17). Se ha postulado que la proteína Tax, producto de expresión viral con efecto oncogénico, es necesaria pero no suficiente para la transformación tumoral de los linfocitos T. Los estudios recientes indican que algunas proteínas accesorias del genoma viral podrían estar determinando la progresión del estado asintomático al sintomático, participando en una serie de etapas intermedias del proceso neoplásico que alterarían, entre otros, el ciclo celular de la célula huésped $(16,18,19)$.

Aunque la infección por HTLV-I es un importante problema de salud pública en Colombia, se desconoce la prevalencia de la leucemia/linfoma de células $T$ en adultos asociada. Esto se debe a que no es rutinario, entre el grupo de clínicos, hacer un diagnóstico serológico para la infección 
en los casos confirmados de leucemia/linfoma de células $T$ en adultos (20).

En este estudio se analizó la presencia del provirus HTLV-I en biopsias ganglionares y en células mononucleares de sangre periférica de 75 pacientes colombianos con diagnóstico de leucemia, que ingresaron al Hospital Universitario del Valle "Evaristo García" entre 1998 y 2003. En las muestras positivas para el HTLV-I se logró confirmar la expansión clónica. Se caracterizó el ADN adyacente a las puntos de integración del provirus del HTLV-I mediante un estudio in silico de 28 secuencias del genoma humano que se encuentran al lado de los sitios de integración proviral, provenientes de pacientes con leucemia/ linfoma colombianos y 33 secuencias de origen japonés.

Los hallazgos corroboraron la presencia de clones de células tumorales y permitieron concluir que en esta enfermedad, la integración del HTLV-I no es al azar. Las regiones blanco de integración se asociaron con secuencias ricas en GC que definen un ambiente genómico rico en genes localizados en regiones de cromatina de replicación temprana, que intervienen en el ciclo celular y la transducción de señales de la célula hospedera.

\section{Materiales y métodos}

\section{Pacientes y muestras}

Se incluyeron biopsias ganglionares de 73 pacientes que ingresaron al Hospital Universitario "Evaristo García" de Cali entre 1998 y 2003, con diagnóstico clínico de leucemia. Estas biopsias, embebidas en parafina, fueron remitidas al Departamento de Patología de la Universidad del Valle, en Cali, para su revisión y diagnóstico histopatológico de leucemia/linfoma de células T en adultos. De las muestras incluidas, $66,7 \%$ eran de hombres y $33,3 \%$ de mujeres, con un rango de edades entre 5 y 88 años (media $=42,5$ ). De cada uno de los casos, se obtuvieron datos relacionados con la condición patológica y pruebas de laboratorio, así como el origen geográfico, los cuales se consignaron en la historia clínica existente. Además, se estudiaron dos muestras de células mononucleares de sangre periférica de dos pacientes leucémicos diagnosticados serológicamente como portadores del HTLV-I.

El acceso a las muestras de tejido y a las de sangre recolectadas a los individuos con diagnóstico de leucemia y serología positiva para HTLV-I (leucemia/linfoma de células $T$ en adultos/HTLV-I), se realizó, luego, de la aprobación por parte del Comité de Ética de la Universidad del Valle, así como el del Hospital Universitario "Evaristo García” (21).

\section{Extracción del ADN}

EI ADN de los tejidos embebidos en parafina se obtuvo siguiendo las instrucciones del estuche comercial EX-WAX ${ }^{\circledR}$ especialmente diseñado para tejidos parafinados (Chemicon Internacional, Temecula, CA). Para dos casos de leucemia, a partir de sangre completa, mediante gradientes de Ficoll Hipaque, se obtuvieron células mononucleares de sangre periférica (22). El ADN se extrajo utilizando el estuche WizardGenomic DNA Purification ${ }^{\circledR}$ (Promega, Madison, WI). El grado de pureza y la concentración del ADN extraído se evaluó por espectrofotometría.

\section{Hibridación de ADN}

Una alícuota de $10 \mathrm{ng} / \mathrm{ml}$ de cada uno de los ADN extraídos se inmovilizó en membranas de nailon. Fueron colocados, de forma independiente en posiciones registrables sobre la membrana, con ayuda de un equipo para transferir por vacío. El ADN se fijó a la membrana mediante irradiación con luz ultravioleta en un aparato de entrecruzado de luz ultravioleta (Stratalinker UV Crosslinker $\AA^{\circ}$, Stratagene, Santa Clara, CA), de acuerdo con las condiciones recomendadas por el fabricante. Posteriormente, las membranas, se incubaron durante 16 horas con la mezcla apropiada de hibridación.

Como sonda se utilizó el plásmido pMT2, el cual contenía la secuencia de ADN completa del HTLV-I de la cepa de referencia MT2 (23). Esta sonda se marcó no radiactivamente con digoxigenina-dUTP, usando el estuche comercial DIG DNA Labeling and Detection (Boehringer Mannheim, Germany), siguiendo un protocolo ajustado en el laboratorio a partir del método de 
Feinberg et al. (24). Después de la hibridación, la membrana se sometió a varios procesos de lavado y posterior revelado siguiendo el protocolo del estuche comercial; para ello se usó una película de rayos $X$ de alto contraste (Cronex® 10T, Agfa). Ésta se expuso en la oscuridad sobre la membrana hibridada durante tiempos variables. Después del proceso de revelado, aquellas muestras que presentaban una mancha negra correspondiente a la señal de hibridación en la película, se clasificaron como positivas para la presencia del ADN proviral del HTLV-I. Como control interno de hibridación, se utilizó una sonda comercial de $\beta$-globina.

\section{Amplificación del ADN de las secuencias LTR y del gen tax del HTLV-I}

Los ADN de las diferentes muestras incluidas en este trabajo se sometieron a un proceso de PCR anidada con oligonucleótidos cebadores específicos para el gen tax y la región LTR que fueron sintetizados a partir de las secuencias de nucleótidos correspondientes de la cepa de referencia ATK1 (23). Los oligonucleótidos cebadores corresponden a secuencias de nucleótidos de tamaño variable, sintetizadas químicamente. Todas las reacciones de la PCR anidada se realizaron siguiendo las condiciones de reacción previamente descritas (25).

El proceso completo incluyó una primera amplificación de la región del gen tax con los oligonucleótidos cebadores externos PXO1+, 5'TCGAAACAGCCCTGCAGATA-3'(7257-7276) y PXO2-, 5'-TGAGCTTATAGATTTGTCTTCA3'(8447-8467). Un segundo ciclo de amplificación se llevó a cabo con los cebadores internos PXI1+, 5'-ATACAAAGTTAACCATGCTt-3' (7274-7293)y PXI3 5'-AGACGTCAGAGCCTTAGTCT-3 (83748393). Con el uso de los cebadores internos se buscaba incrementar la especificidad y la sensibilidad de la segunda amplificación.

Para amplificar la región LTR, se utilizaron los oligonucleótidos cebadores externos $\mathrm{LTRO} 1^{+}, 5^{\prime}$ ACCATGAGCCCCAAATATCCCCC-3'(9-31) Y LTRO2-, 5'-TCGTATCCCGGACGAGCCCCCAA-3' (757-746) en una primera ronda de PCR; en la segunda ronda se emplearon los cebadores internos LTRI1 ${ }^{+}, 5^{\prime}$-AGACTAAGGCTCTGACGT-
CTCCC-3'(97-119) y LTRI2, 5'-AATTTCTCTCCTGAGAGTGCT-3'(722-746). Lascondiciones de amplificación fueron similares a las aplicadas para la amplificación de la región Tax.

\section{Amplificación del ADN genómico por PCR inversa}

La amplificación de secuencias de ADN celular adyacentes el provirus HTLV-I se efectuó siguiendo un protocolo ya descrito $(26,27)$ con modificaciones menores (28). Todo el proceso incluyó las siguientes etapas: una digestión inicial del ADN extraído con Alul, que reconoce los sitios de restricción localizados en la región U5 de los LTR, uno interno dentro del gen gag del provirus, otro en la región U5 del extremo 5 'LTR y otros externos localizados en el genoma del hospedero. Una segunda etapa incluyó un proceso de autoligación de los extremos cohesivos de cada uno de los fragmentos obtenidos en la etapa anterior, usando la enzima ADN ligasa del fago T4. En una tercera etapa, los fragmentos autoligados se sometieron a digestión con Sstll, endonucleasa de restricción que reconoce específicamente un sitio de corte dentro del gen gag del provirus; mediante este tratamiento se conservaron los anillos de ADN que contenían porciones de genoma del huésped más un fragmento de la región U5 del LTR proviral.

Después de una etapa de calentamiento a $93^{\circ} \mathrm{C}$ por 30 minutos, los círculos relajados fueron amplificados por PCR. Los oligonucleótidos cebadores fueron sintetizados a partir de secuencias específicas de la región U5 del provirus HTLV-I. Previamente a los ciclos de amplificación por PCR, la muestra fue sometida a desnaturalización térmica en las condiciones antes descritas. Como oligonucleótidos cebadores de la PCR se emplearon el HTVL-009, 5'AAGCCGGCAGTCAGTCGTGA-3' (8946-8927) y el HTLV-010, 5'-AAGTACCGGCAACTCTGCTG-3' (8958-8977). El alineamiento de los cebadores se llevó a cabo a $52^{\circ} \mathrm{C}$ por 30 segundos, seguido de una etapa de extensión a $72^{\circ} \mathrm{C}$ por 90 segundos. El número de ciclos de amplificación PCR inversa fue de 35 en total.

Todos los productos de la PCR inversa se separaron, de acuerdo con su tamaño molecular, 
en pares de bases, mediante electroforesis en geles de agarosa al $2 \%$. La visualización de las bandas de ADN se registró por la fluorescencia del bromuro de etidio unido al ADN. El grado de expansión clónica y el número de clones se calcularon por conteo directo sobre el gel del número de bandas de ADN de los amplicones IPCR; cada banda representaba un clon celular.

\section{Protocolos de clonación y secuenciación}

Los fragmentos de ADN obtenidos por PCR inversa, se eluyeron de los geles de agarosa usando el estuche comercial QIAEX II Gel Extraction ${ }^{\circledR}$ (Qiagen, Valencia, CA). Los fragmentos de ADN eluidos se ligaron al sitio Hind III del plásmido vector pCR2.1, previamente alineado con la misma enzima. Los plásmidos recombinantes se transformaron en células de Escherichia coli, cepa DH5a, siguiendo las instrucciones del estuche comercial TA Cloning System ${ }^{\circledR}$ (In VitroGen, Carisbad, CA). Los recombinantes obtenidos por extracción de ADN en lisis alcalina, se digirieron con EcoR I para liberar el fragmento de ADN celular clonado. En total, se obtuvieron 28 clones por PCR inversa del HTLV-I en los pacientes colombianos con diagnóstico de leucemia/linfoma. El ADN celular clonado se secuenció empleando el método de secuenciación cíclica en un secuenciador $A B I$ PRISM 310; (PE Applied Biosystems, Norwalk, CONN).

\section{Obtención de secuencias por PCR inversa de pacientes leucemia/linfoma de células $T$ en adultos del Japón}

Mediante búsqueda en la base mundial de datos GenBank (http://www.ncbi.nlm.nih.gov), se seleccionaron 33 secuencias de PCR inversa, provenientes de pacientes japoneses con diagnóstico confirmado de leucemia/linfoma de células $\mathrm{T}$ en adultos/HTLV-I+ ${ }^{+}$, depositadas por Ozawa et al., cuyos códigos de acceso van del AB114357 al AB114390 (29).

\section{Alineamientos y asignación de secuencias por PCR inversa}

Con el fin de eliminar la contaminación de porciones de secuencias LTR virales, las 61 secuencias por PCR inversa incluidas en este trabajo se analizaron mediante el programa de Vector Screen de acceso público (www. ncbi.nlm.nih.gov/vecscreer/vecscree.html). Las secuencias de nucleótidos ya editadas se alinearon, utilizando el programa Blast-N (http:// www.ncbi.nlm.nih.gov/blast/) con porciones de ADN humano. Para este estudio se utilizaron solamente aquellas secuencias con grados de homología $\geq 95 \%$ (e-value $\leq 0,05$ ). Los tamaños de éstas variaron de 50 a 1.000 pb.

La localización cromosómica, los genes anotados, los elementos repetidos y otras características de la cromatina adyacente a los provirus HTLV-I (orientación, proceso biológico en el que intervienen, función molecular y ubicación celular), se llevaron a cabo utilizando las herramientas computacionales disponibles en la página web del National Center for Biotechnology Information (NCBI) de los Estados Unidos, y en la base de datos del Genome Browser de la Universidad de California en Santa Cruz (http://genome.ucsc.edu/).

Además, se complementó con información anotada en las bases de datos Gencard (http://www. genecards.org/cgi-bin/carddisp.pl); Gene Entrez (http://www.ncbi.nlm.nih.gov/ncbi/gene-entrez) y Gene Ontology (GO) (http://www.geneontology. org/index.shtml).

Los análisis estadísticos se realizaron utilizando el paquete Stata, versión 8.0 (30). Las diferencias entre la composición de nucleótidos de las secuencias adyacentes a los sitios de integración se establecieron mediante la prueba t de Student. Las diferencias estadísticas entre el tipo de secuencia adyacente al ADN proviral y la frecuencia de estas secuencias en el genoma humano según Venter et al. (31), y las del IHGSC-2001 (International Human Genome Sequencing Consortium) (32), se calcularon con la prueba de ji al cuadrado, en donde un valor de $p<0,05$ fue considerado como estadísticamente significante. La correlación entre el tamaño del cromosoma y el número de integraciones se estableció mediante el coeficiente ro de Spearman. La correlación entre el número de integraciones y la relación del tiempo de replicación, se determinó mediante un análisis 
de correlación lineal $\mathrm{R}$ de acuerdo con los datos de obtenidos por Woodfine et al. (12) (figura 1).

\section{Resultados}

\section{Casos colombianos de leucemia/linfoma de células $T$ en adultos positivos para HTLV-I}

Las características generales de los casos de leucemia/linfoma de células $T$ en adultos/ HTLV-I+ según los hallazgos del estudio se resumen en el cuadro 1. Los resultados de la hibridación en Southern usando como sonda el pMT2 y los de la PCR anidada del gen tax y LTR del provirus, permitieron clasificar $8 \%(6 / 75)$ de las muestras como leucemia/linfoma de células T en adultos/HTLV-I+ (cuadro 1). Solamente Colleu-2189 no mostró señal de hibridación; sin embargo, en ésta se logró amplificar tanto sus secuencias LTR como las del gen tax, por lo cual fue incluida como positiva para el virus en los estudios posteriores.

\section{Expansión clónica y composición de nucleótidos}

De los siete pacientes colombianos con leucemia/linfoma de células $\mathrm{T}$ en adultos/HTLV-I ${ }^{+}$ estudiados en este trabajo, cinco mostraron un bajo nivel de expansión clónica que correspondió a un número de clones menor de 10 (figura 2). En dos casos, Col-leu-2189 y Col-leu-220, se observó un patrón de expansión monoclónica (figura 2). El promedio del número de amplicones por PCR inversa en los pacientes colombianos

(A)

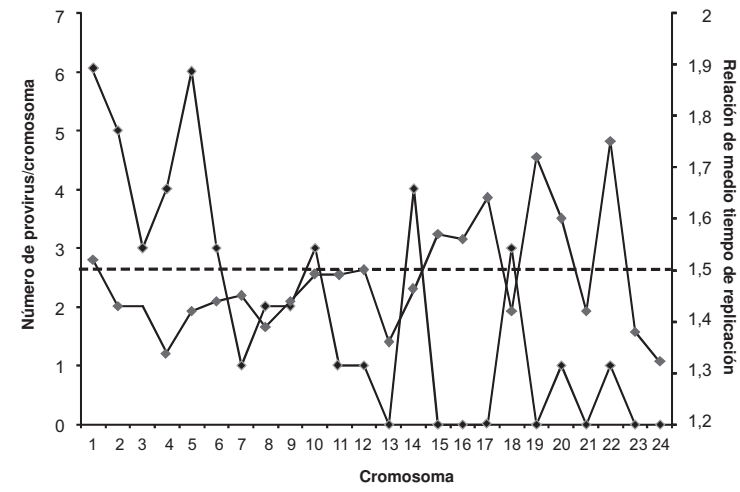

fue de 5,8, con un rango de 1 a 10 , cuyos tamaños variaron entre 50 y 1.000 pb.

El porcentaje de los cuatro nucleótidos en una región de $50 \mathrm{pb}$ del ADN celular vecino a los sitios de integración del provirus HTLV-I fue de $24,7 \%$ A, $19,6 \%$ T, 28,6\% G y 2,5\% C (figura $3)$. El promedio de contenido de G:C en el ADN celular de los flancos de los pacientes con leucemia/linfoma de células T en adultos/HTLV-I+ fue $56,1 \pm 12,9 \%$; éste fue estadísticamente significativo con respecto al promedio tomado de 600 secuencias al azar del genoma humano $(42,2 \pm 6,3 \%)(p<0,05)$.

\section{Asignación cromosómica de las secuencias por PCR inversa}

Los alineamientos de secuencias por PCR inversa con las bases de datos incluidas en este trabajo, se iniciaron en agosto y finalizaron en noviembre de 2007. Para los análisis posteriores, se consideró una ventana de apertura de 100 a $200 \mathrm{kpb}$. En estas condiciones, se obtuvieron 155 hits con homologías $\geq 95 \%$, que es consideraba como estadísticamente significante (e-value $\leq 0,05)$. Los hits incluyeron secuencias de ADN codificantes (37/155) y secuencias repetitivas (116/155). El 45,95\% (17/37) de las integraciones se localizaron en regiones del exón del genoma. En 21 de estos genes, la integración, ocurrió en la cadena positiva, en la dirección correcta de transcripción.

(B)

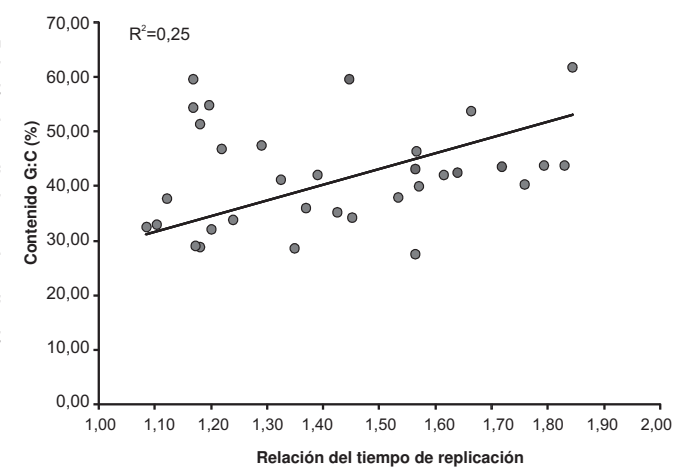

Figura 1. Correlación entre el número de integraciones del HTLV-I registradas en este estudio, con el tiempo de replicación relativo según Woodfine et al. (12), y contenido en C:G del correspondiente locus cromosómico según Venter et al. (28) (figura A). Relación de los tiempos de replicación cromosómica según Woodfine et al. y el número de integraciones por cromosomas (figura B). 
Los resultados mostraron una mayor tendencia de eventos de integración hacia cromosomas con relaciones de tiempos de replicación mayores que 1,5 (los cuales se consideran como de replicación temprana) (12) y en regiones cromosómicas con alto contenido C:G (figura 4). El mayor número de eventos de integración se registró en los cromosomas grandes y medianos de los grupos A, B y C (ro de
Spearman, $p>0,05)$. En las muestras incluidas en este trabajo, no se registraron provirus en los cromosomas 7, 9, 13, 15, 19, 21, X y $Y$ (figura 3). La distribución cromosómica de estos provirus, mostró una tendencia a concentrarse en regiones teloméricas y subcentroméricas, sin diferencias significativas en esta distribución, según el tipo de secuencia codificante o no codificante (figura 4). Esta asignación cromosómica de provirus

Cuadro 1. Características generales de los pacientes colombianos con leucemia/linfoma positivos para el HTLV-I.

\begin{tabular}{lcccclccc}
\hline Código & $\begin{array}{c}\text { Diagnóstico } \\
\text { patológico }\end{array}$ & $\begin{array}{c}\text { Tipo de } \\
\text { muestra }\end{array}$ & Sexo & Edad & Origen & PCR § & $\begin{array}{c}\text { Hibridación } \\
\left({ }^{*}\right)\end{array}$ & $\begin{array}{c}\text { Número de } \\
\text { amplicones } \\
\text { IPCR }\end{array}$ \\
\hline Col-leu-144 & 1 & a & M & 61 & Cali & ++ & + & 10 \\
Col-leu-962 & 1 & b & M & 32 & Bocas Satinga & ++ & + & 3 \\
Col-leu-322 & 2 & b & M & 29 & Buenaventura & ++ & + & 9 \\
Col-leu-3139 & 2 & b & M & 37 & Barbacoas & ++ & + & 9 \\
Col-leu-2189 & 3 & C & H & 59 & Cali & + & - & 1 \\
Col-leu-220 & 2 & d & H & 42 & Cali & ++ & + & 1 \\
Col-leu-167 & 2 & d & M & 56 & Cali & ++ & + & 8 \\
\hline
\end{tabular}

1: difuso con células grandes y pequeñas, 2 : difuso con células grandes; 3 : difuso con células cerebriformes de gran tamaño; a: ganglio axilar com linfoma; b: ganglio de linfoma no especificado; c: ganglio de linfoma retroperitoneal; d: linfocitos de sangre periférica.

§: PCR inversa con tax y LTR; ++: amplificación con ambos oligonucleótidos cebadores; +: amplificación solamente con los oligonucleótidos cebadores para LTR; *: resultado de hibridación de ADN por quimioluminiscencia; +: sonda de hibridación con pMT2; -: sin hibridación con la sonda pMT2; ¥: se calculó como el número de amplicones de PCR inversa obtenidos del ADN de cada una de las muestras de leucemia/linfoma de células T en adultos positivas para HTLV-I; M: mujer; H: hombre.

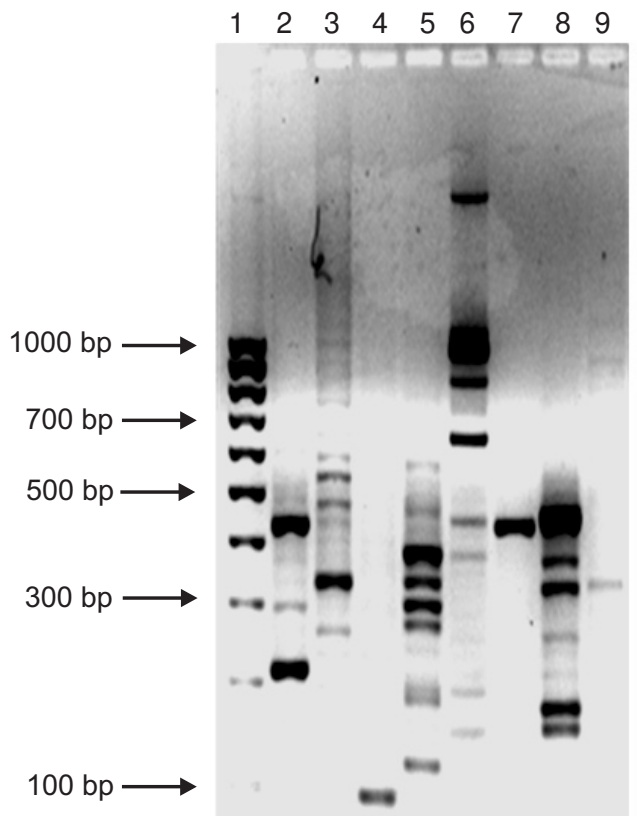

Figura 2. Patrones de expansión clonal en siete casos colombianos leucemia/linfoma de células T en adultos/HTLV-I+ del Hospital Universitario del Valle "Evaristo García" de Cali, Colombia. Electroforesis de los productos de la PCR inversa realizados con ADN de cinco biopsias nodulares y dos muestras de células mononucleares de sangre periférica. La leucemia es resultado de la expansión de poblaciones celulares clónicas, las cuales en una electroforesis se observan como bandas de ADN de diferente tamaño sobre el gel; se define como monoclónica cuando se observa una sola banda y, oligoclónica, cuando hay presencia de varias bandas de ADN obtenido por PCR inversa. (1) Marcador de tamaño molecular en pares de bases correspondiente a la escalera de 100 pb. (2) Línea celular MT4. (3) Col-leu144. (4) Col-leu-2189. (5) Col-leu-3139. (6) Colleu-322. (7) Col-leu-220. (8) Col- leu-167. (9) Col-leu-962. Las flechas indican la migración de los fragmentos de ADN en pares de bases de la escalera de $100 \mathrm{pb}$. 


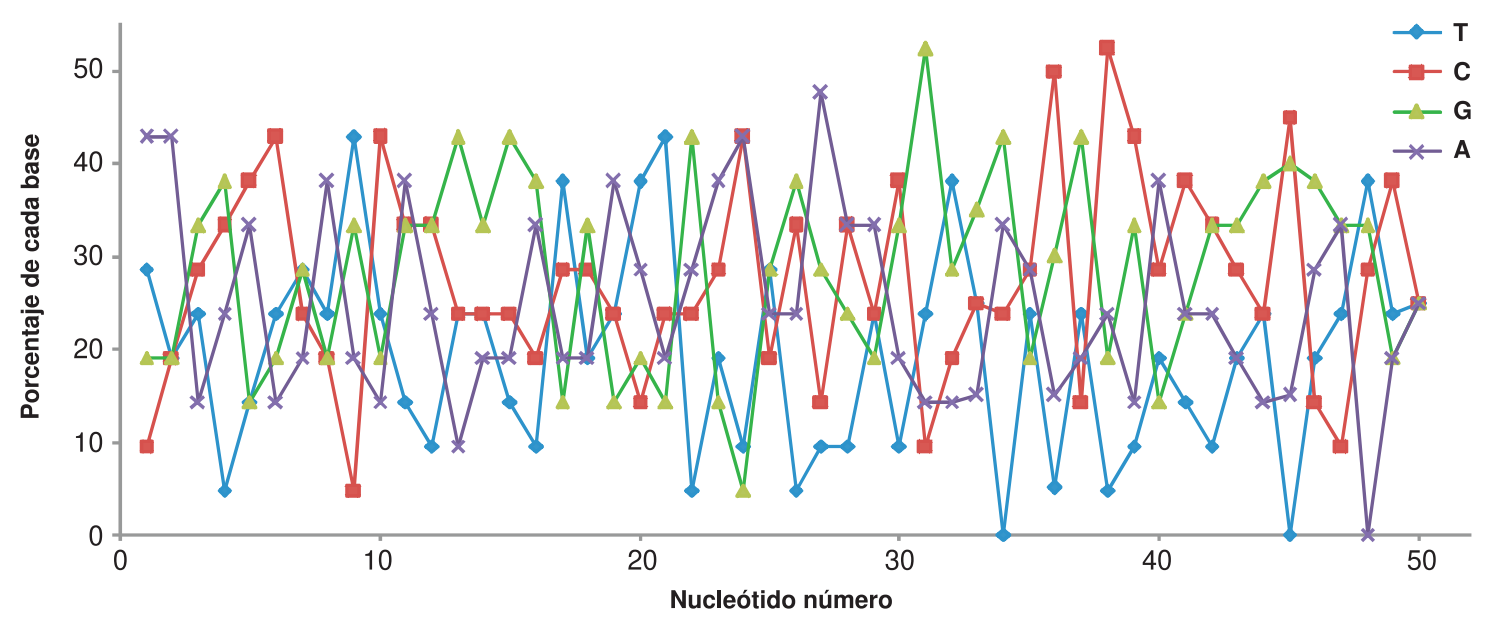

Figura 3. Distribución del contenido de GC por nucleótido en regiones de genoma humano de 50 pb adyacentes a los sitios de integración de provirus en pacientes colombianos con leucemia/linfoma de células T en adultos.

HTLV-I fue semejante en las secuencias tanto de pacientes colombianos como de japoneses $(p>0,05)$.

\section{Ambiente genómico de las zonas adyacentes a los provirus}

El $74,84 \%(116 / 155)$ de los alineamientos ocurrieron en porciones no codificantes del genoma humano, mientras que el $25,16 \%$ (39/155) correspondieron a genes anotados en las bases Gene Entrez y Genecard (cuadro 2).

De acuerdo con el grado de repetición, 56,04\% (65/116) correspondieron a secuencias SINE y transposones y elementos retrovirales (figura 5a). Al compararse el porcentaje de esta distribución con aquéllas reportadas por Venter et al. (31) ,y el International Human Genome Sequencing Consortium (IHGSC) (32) para el total del genoma humano, se observaron diferencias estadísticamente significativas $(p<0,05)$ (cuadro 2). Además, la comparación del porcentaje del total de genes del genoma $(31,32)$, en relación con la frecuencia de aquellos genes localizados en los sitios de integración proviral, también mostró diferencias estadísticamente significativas $(p<0,05)$.

Los genes identificados en los sitios de integración, se clasificaron según el proceso biológico en el que intervienen, la función molecular y la ubicación subcelular. En relación con el proceso biológico, los más frecuentes (25/37) correspondieron a genes reguladores del ciclo celular, de transducción de señales y de regulación de la expresión de otros genes (figura 5b). De acuerdo con su función celular, fueron más frecuentes los genes con funciones receptoras, de unión a moléculas y factores de transcripción (figura 5c). En el 37,84\% (14/37) de los genes identificados con el estudio in silico, sus productos génicos se localizan en el núcleo (figura 5d).

Una caracterización más detallada que incluyó el locus cromosómico, sitio exacto de integración dentro del gen, y la orientación de transcripción de la cadena, se presentan en el cuadro 3.

\section{Discusión}

Aunque la infección por el HTLV-I en Colombia es un problema importante de salud pública, su asociación con hemopatías ha sido poco explorada. Los datos de prevalencia obtenidos de la cohorte incluida en este estudio, proveniente de una institución universitaria de salud de nivel 3, mostraron una prevalencia de $8,8 \%$ de positividad parael HTLV-l; éste es el primer reporte epidemiológico en el suroccidente colombiano, en un tamaño de muestra significativo, en donde se confirma, mediante estudios moleculares directamente efectuados sobre tejido tumoral y células mononucleares de sangre periférica, 


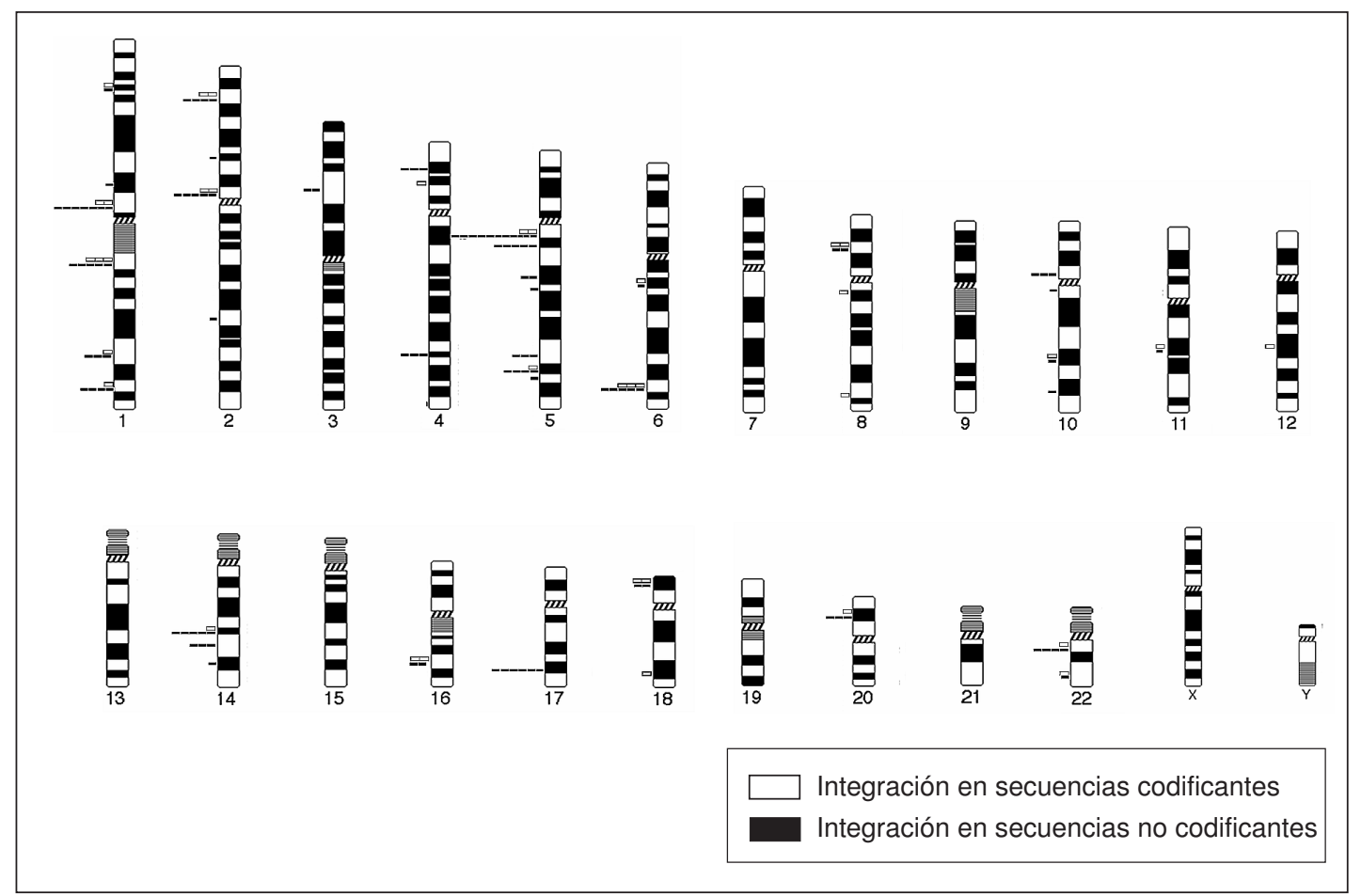

Figura 4. Localización cromosómica de 155 integraciones del provirus HTLV-I de pacientes con leucemia/linfoma de células T en adultos. Los sitios de integración fueron asignados según la información del Gene Entrez y el Genecard. Los cuadros blancos muestran zonas de integración dentro de secuencias codificantes; los cuadros negros corresponde a la localización de integraciones en secuencias no codificantes.

la presencia de secuencias provirales (LTR y tax) en pacientes con diagnóstico clínico de leucemia/linfoma. Solamente en un reporte previo se determinó la presencia del retrovirus a partir de muestras de linfocitos de sangre periférica en casos aislados de leucemia de pacientes colombianos (33).

La existencia de un bajo número de expansión oligoclónica en las muestras estudiadas, así como un alto contenido de C:G en una región de 50 $\mathrm{pb}$ del genoma humano adyacentes a provirus HTLV-I, concuerdan con resultados previos obtenidos por otros autores $(34,35)$. Sin embargo, es importante destacar que este tipo de hallazgo ha sido muy frecuentemente reportado en muestras de sangre, a diferencia de los resultados obtenidos en este estudio en el que se efectuó tanto en sangre como en biopsias ganglionares.

Un aspecto interesante de este trabajo fue el haber determinado que el mayor número de integraciones ocurrió en el $71,9 \%$ del total de la cromatina celular (31), involucrando los cromosomas de gran tamaño; este resultado coincide con los de Doi et al. (36) y Hanai et al. (37), en los que se referencia la asignación cromosómica. Utilizando cromosomas artificiales con tamaños variables (0,5 a 1,6 Mbp), se ha demostrado que cuando disminuye el tamaño cromosómico se incrementa la relación de pérdidas de ADN y, por lo tanto, se compromete la estabilidad del cromosoma (38). Con base en estas evidencias experimentales, y a la luz de los resultados obtenidos en este trabajo, se podría proponer que la integración proviral del HTLV-I es favorecida por una estabilidad mitótica, la cual sería dependiente del tamaño del cromosoma blanco de integración.

Las características de la composición de la cromatina adyacente a los sitios de integración, se comportan como variables; el contenido de 
A

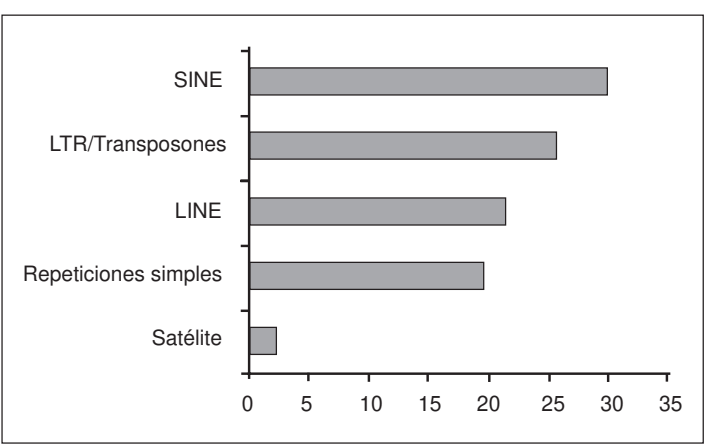

C

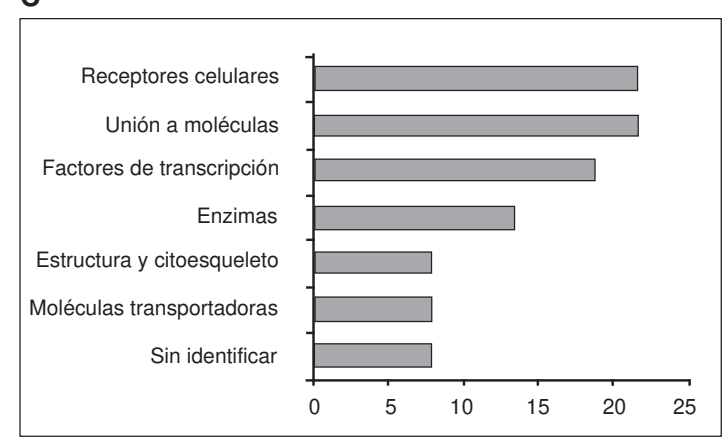

B

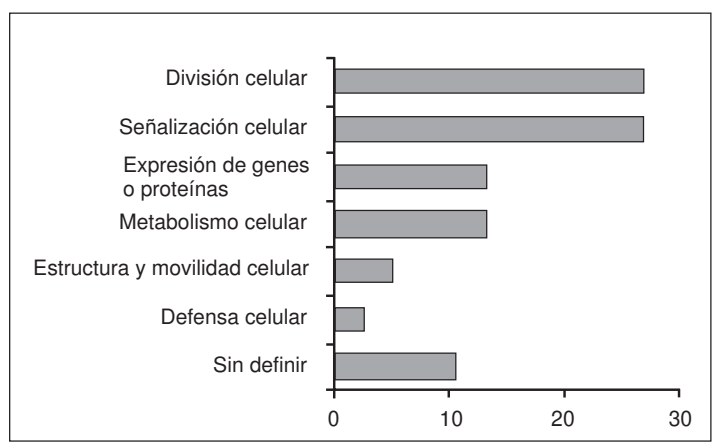

D

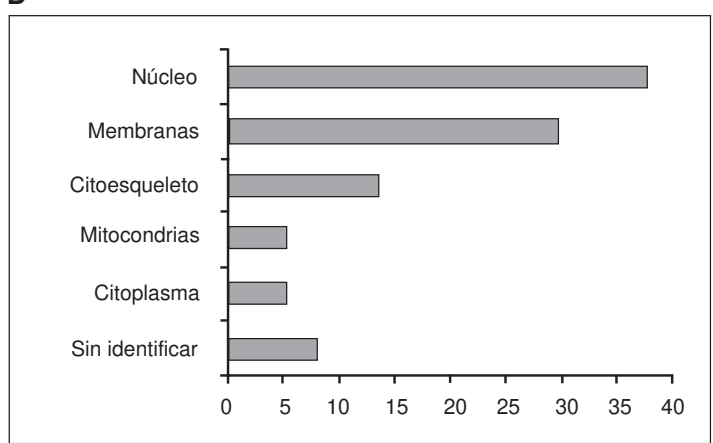

Figura 5. Distribución de las secuencias homólogas a las secuencias por PCR inversa en estudio según tipo de secuencia repetitiva (figura A), proceso biológico (figura B), función celular (figura C) y ubicación subcelular (figura D) según la base de datos de Gen Ontology (GO).

Cuadro 2. Características generales y correlación de las secuencias homólogas a las secuencias por PCR inversa en estudio. Los datos de porcentajes de secuencias génicas y repetitivas en el genoma humano fueron tomadas de Venter et al. (28), y del International Human Genome Sequencing Consortium (IHGSC) (31).

\begin{tabular}{lccc}
\hline Clase de secuencias & $\begin{array}{c}\text { Número de potenciales } \\
\text { sitios de integración } \\
\text { (porcentaje) }\end{array}$ & $\begin{array}{c}\text { Número en miles } \\
\text { (porcentaje en el } \\
\text { genoma humano) }\end{array}$ & $\mathbf{P}^{*}$ \\
\hline $\begin{array}{l}\text { Unidades de transcripción } \\
\text { Genes }\end{array}$ & $37(24,18)$ & $30-40(1,4)$ & $\mathrm{P}<0,05 \mathrm{~s}$ \\
Elementos repetitivos & $25(16,33)$ & $868(21)$ & $\mathrm{P}=0,7284 \mathrm{~ns}$ \\
LINE & $35(22,87)$ & $1.558(13)$ & $\mathrm{P}<0,05 \mathrm{~s}$ \\
SINE & $3(2,0)$ & $\mathrm{Nc}$ & $\mathrm{nc}$ \\
Satélite & $23(15,03)$ & $762(8)$ & $\mathrm{P}<0,05 \mathrm{~ns}$ \\
Repeticiones simples & $30(19,60)$ & $737(11)$ & $\mathrm{P}<0,05 \mathrm{~s}$ \\
Transposones y elementos retrovirales & &
\end{tabular}

* valor de p para el ji al cuadrado de dos proporciones independientes; S: estadísticamente significante; ns: estadísticamente no significante; nc: no calculado. 
Cuadro 3. Principales características de los genes que están involucrados en la integración del provirus HTLV-I en pacientes con leucemia/linfoma incluidos en este estudio.

\begin{tabular}{|c|c|c|c|c|c|}
\hline Nombre del gen & $\begin{array}{c}\text { Símbolo } \\
\text { oficial } \\
\text { del gen }\left(^{*}\right)\end{array}$ & $\begin{array}{l}\text { Locus } \\
\text { cromosómico }\end{array}$ & $\begin{array}{l}\text { Número de } \\
\text { identificación } \\
\left({ }^{* \star}\right)\end{array}$ & $\begin{array}{l}\text { Integración } \\
\text { en }\end{array}$ & $\begin{array}{l}\text { Orientación } \\
\text { de la } \\
\text { integración }\end{array}$ \\
\hline Motivo 33 tripartito & Trim33 & $1 \mathrm{p} 13.1$ & 51592 & Exón & Negativa \\
\hline Sinaptogamina VI & Syt6 & $1 \mathrm{p} 13.2$ & 148281 & Exón & Negativa \\
\hline Proteína de dedos de cinc mym tipo 4 & Znf262 & 1p32-p34 & 9202 & Exón & Positiva \\
\hline Caja homeótica 1 de preleucemia de células b & $\mathrm{Pbx} 1$ & $1 \mathrm{q} 23$ & 5087 & Exón & Positiva \\
\hline Componente del cinetocoro homólogo a ndc80 & Nuf2 & $1 \mathrm{q} 23.3$ & 83540 & Exón & Positiva \\
\hline Antígeno cd46 & $\mathrm{Cd} 46$ & $1 \mathrm{q} 32$ & 4179 & Exón & Positiva \\
\hline $\begin{array}{l}\text { Proteína nuclear similar a las del consenso } \\
\text { de valosina }\end{array}$ & $\mathrm{Nvl}$ & $1 q 41-q 42.2$ & 4931 & Exón & Negativa \\
\hline Cinasa de linfoma anaplásico & Alk & $2 \mathrm{p} 23$ & 238 & Exón & Negativa \\
\hline Subnunidad 3 de la ATP sintasa & Atp5g3 & $2 q 31.1$ & 518 & Exón & Negativa \\
\hline Miembro 3 del intercambiador aniónico & Slc2c & $2 q 36$ & 6508 & Exón & \\
\hline Proteína cinasa tryo1 & Epha4 & $2 q 36.1$ & 2043 & Exón & Negativa \\
\hline Antígeno cd38 & Cd38 & $4 \mathrm{p} 15$ & 952 & Exón & Positiva \\
\hline $\begin{array}{l}\text { Proteína } 1 \text { de enlace al factor de crecimiento } \\
\text { de fibroblastos }\end{array}$ & Fgfbp1 & $4 p 16$ & 9982 & Exón & Negativa \\
\hline Factor de coagulación IX & $\mathrm{F} 11$ & $4 q 35$ & 2160 & Exón & Negativa \\
\hline Factor 15 semejante al de ribosilación de ADP & Arl15 & $5 p 15.2$ & 54622 & Exón & Negativa \\
\hline $\begin{array}{l}\text { Miembro } 8 \text { de la familia de las poli(ADP-ribosa) } \\
\text { polimerasas }\end{array}$ & Parp8 & $5 q 11.1$ & 79668 & Exón & Positiva \\
\hline $\begin{array}{l}\text { Miembro a de la familia con similitud de } \\
\text { secuencia } 46\end{array}$ & Fam46a & $6 q 14$ & 55603 & Exón & Negativa \\
\hline lodotirosina desiodinasa & lyd & $6 q 25.1$ & 389434 & Exón & Positiva \\
\hline Dominio con homología a la pleckstrina & Plekhg1 & $6 q 25.1$ & 57480 & Exón & Positiva \\
\hline Proteína corregulada por parkina 2 & Pacrg & $6 q 26$ & 135138 & Exón & Positiva \\
\hline Ankirina isoforma 1 eritrocítica & Ank1 & 8p11.1 & 286 & Exón & Negativa \\
\hline Sintenina & Sdcbp & $8 q 12$ & 6386 & Exón & Positiva \\
\hline Receptor ionotrópico delta 1 del glutamato & Grid1 & $10 q 22$ & 2894 & Exón & Negativa \\
\hline $\begin{array}{l}\text { Proteína } 4 \text { homóloga a la de pair rule oz/tem de } \\
\text { Drosophila, tenascin m4 }\end{array}$ & Odz4 & $11 q 14.1$ & 26011 & Exón & Negativa \\
\hline Factor miogénico 6 o herculina & Myf6 & $12 q 21$ & 4618 & Exón & Positiva \\
\hline Gefirina & Gphn & $14 \mathrm{q} 23.3$ & 10243 & Exón & Positiva \\
\hline Proteína 720 de dedos de zinc & Znf720 & $16 \mathrm{p} 11.2$ & 124411 & Exón & Positiva \\
\hline $\begin{array}{l}\text { Isoforma } 1 \text { de la subunidad IV de la citocromo } \\
\text { C oxidasa }\end{array}$ & Cox4i1 & 16q22-qter & 1327 & Exón & Positiva \\
\hline Factor 8 regulador del interferón & Irf8 & $16 q 24.1$ & 3394 & Exón & Positiva \\
\hline Proteína I3mbt4 semejante a la de Drosophila & L3mbtl4 & $18 p 11.31$ & 91133 & Exón & Negativa \\
\hline Componente del cinetocoro homólogo a ndc 80 & Ndc80 & $18 p 11.32$ & 10403 & Exón & Positiva \\
\hline Antígeno cd226 & Cd226 & $18 q 22.3$ & 10666 & Exón & Negativa \\
\hline Treonina aspartasa 1, (taspasa) & Tasp1 & 20p12.1 & 55617 & Exón & Negativa \\
\hline $\begin{array}{l}\text { Proteína } 1 \text { candidata al síndrome de } \\
\text { Schmid-Fraccaro }\end{array}$ & Cecr1 & $22 q 11.2$ & 51816 & Exón & Negativa \\
\hline Cadena pesada 9 de la miosina no muscular & Myh9 & 22q13.1 & 4627 & Exón & Negativa \\
\hline
\end{tabular}

*: la abreviatura según lo consignado en la base de datos del National Center for Biotechnology Information (NCBI) de los Estados Unidos (http://www.ncbi.nih.gov); **: obtenido de la base de datos Entrez Gene del NCBI y GeneCard.

G:C $(4,8-11,39,40)$, la densidad de islas CpG $(11,13)$, la densidad de genes $(13,15)$, los tiempos de replicación $(12,14,15)$ y eventos de recombinación y mutación $(17,41,42)$ de porciones de cromatina que están constantemente sometidas a procesos de remodelación por eventos epigenéticos $(17,42,43)$, constituyeron el microambiente genómico asociado con una mayor concentración de integraciones provirales identificadas en este trabajo. Una posible explicación a este hecho debe incluir el estado de conformación de la cromatina en el momento de la integración. Trabajos previos (44-47) han puesto de manifiesto la importancia de la estructura de la cromatina en la integración retroviral, puesto que una conformación más 
relajada aumentaría la accesibilidad de los complejos remodeladores de la cromatina que regularían la integración retroviral (45).

Se ha identificado previamente que las secuencias SINE-Alu actúan como promotores alternos para la expresión de genes $(42,48)$. La gran frecuencia de integraciones dentro de elementos repetidos tipo SINE, reportada en este trabajo, podría explicar las alteraciones en la expresión de genes asociados con el ciclo celular, la transducción de señales y la regulación de la expresión de genes, situaciones previamente reportadas en los procesos leucomogénicos.

En general, los resultados de este trabajo presentan indicios muy sólidos que sustentan una integración retroviral, no al azar. Algunas características estructurales y funcionales, promoverían eventos de integración preferencial hacia regiones de cromatina sometidas a un intenso proceso de remodelación por mecanismos epigenéticos; éstos condicionarían la topología del ambiente genómico apropiado para la integración. Como efecto de este proceso se alteraría la homeostasis celular, promoviendo el desarrollo de la neoplasia.

\section{Agradecimientos}

A todos los pacientes con leucemia/linfoma de células $\mathrm{T}$ en adultos/HTLV-I+ incluidos en este estudio quienes, mediante su colaboración, permitieron ampliar el conocimiento de la leucemia/ linfoma de células $T$ en adultos en el contexto de la infección por HTLV-I en Colombia.

\section{Conflictos de interés}

Los investigadores declaran que no existe ningún tipo de conflicto de intereses con respeto a los resultados de esta investigación.

\section{Financiación}

Este trabajo se realizó en el marco de un proyecto de Colciencias (contrato RC-5422002), cofinanciado por la Universidad del Valle, el Ministerio de Cultura y Educación del Japón y la Universidad de Kagoshima; además, con recursos proporcionados por la Vicerrectoría de Investigaciones de la Universidad del Valle bajo el acta de trabajo y compromiso 1576 del 2008.

\section{Referencias}

1. Poiesz BJ, Ruscetti FW, Gadzar AF, Bunn PA, Minna JD, Gallo RC. Detection and isolation of type C retrovirus particles from fresh and cultured lymphocytes of a patient with cutaneous T-cell lymphoma. Proc Natl Acad Sci USA. 1980;77:7415-9.

2. Edlich RF, Arnette JA, Williams FM. Global epidemic of human T-cell lymphotropic virus type-I (HTLV-I). J Emerg Med. 2000;18:109-19.

3. Quintana M, Villalobos J, Domínguez M, Tamayo O, García-Vallejo F. Estudio de la seroprevalencia de la infección por los virus linfotrópicos humanos (HTLV) I y II en poblaciones del departamento de Córdoba, Colombia. Colombia Médica. 2004;35:22-30.

4. García-Vallejo F. Caracterización molecular y genómica del proceso de integración del provirus del virus linfotropico humano (HTLV) tipo I. Rev Acad Colomb Cienc. 2006;30:155-70.

5. Yoshida M, Seiki M, Yamaguchi K, Takatsuki K. Monoclonal integration of human T-cell leukemia provirus in all primary tumors of adult T-cell leukemia suggests causative role of human T-cell leukemia virus in the disease. Proc Natl Acad Sci USA.1984;81:2534-7.

6. Yoshida M. Multiple viral strategies of HTLV-1 for dysregulation of cell growth control. Annu Rev Immunol. 2001;19:475-96.

7. Leclerq I, Mortreux F, Gabet AS, Jonson CB, Wattel E. Basis of HTLV type I site selection. AIDS Res Hum Retroviruses. 2000;16:1653-9.

8. Zoubak S, Richardson J, Rynditch AV, Hollsberg P, Hafler DA, Boeri E, et al. Regional specificity of HTLV-I proviral integration in the human genome. Gene. 1994;143:155-63.

9. Glukhova LA, Zoubak SV, Rynditch AV, Miller GG, Titova IV, Vorovyeva N, et al. Localization of HTLV-1 and HIV-1 proviral sequences in chromosomes of persistently infected cells. Chromosome Res.1999;7:177-83.

10. Richarsond JH, Rose NJ, Mann S, Ferguson-Smith M, Lever AM. Chromosomal positioning of human T-lymphotropic type I proviruses by fluorescent in situ hybridisation. J Virol Methods. 2001;93 65-74.

11. Saccone S, De Sario A, Wiegant J, Raap AK, DellaValle G, Bernardi G. Correlations between isochores and chromosomal bands in the human genome. Proc Natl Acad Sci USA. 1993;90:11929-33.

12. Woodfine K, Fiegler H, Beare DM, Collins JE, McCann OT, Young BD, et al. Replication timing of the human genome. Hum Mol Genet. 2004;13:191-202.

13. Saccone S, Cacciò S, Kusuda J, Andreozzi L, Bernardi G. Identification of the gene-richest bands in human chromosomes. Gene. 1996;174:85-94.

14. Kim MA, Johannsmann R, Grzeschik KH. Giemsa staining of the sites replicating DNA early in human 
lymphocyte chromosomes. Cytogenet Cell Genet. 1975;15:363-71.

15. Federico C, Saccone S, Bernardi G. The gene-richest bands of human chromosomes replicate at the onset of the S-phase. Cytogenet Cell Genet. 1998;80:83-8.

16. Albrecht B, Lairmore MD. Critical role of human T-lymphotropic virus type 1 accessory proteins in viral replication and pathogenesis. Microbiol Mol Biol Rev. 2002;66:396-406.

17. Yasunaga JI, Matsuoka M. Human T-cell leukemia virus type I induces adult T-cell leukemia: From clinical aspects to molecular mechanisms. Cancer Control. 2007;14:13340.

18. Albrecht B, Collins ND, Burrinstom MT, Nisbet JW, Ratner L, Green PL, et al. Human T-lymphotropic virus type I open reading frame I p12(I) is required for efficient viral infectivity in primary lymphocytes. J Virol. 2000;74:9828-35.

19. Bindhu M, Nair A, Lairmore MD. Role of accessory proteins of HTLV-1 in viral replication, T cell activation, and cellular gene expression. Front Biosci. 2004;9: 2556-76.

20. Carrascal E, Cortés A, Akiba S, Tamayo O, Quiñónez F, Floréz L, et al. Epidemiología y patología de la leucemia/ linfoma de células T del adulto en Cali y el suroccidente colombiano. Colombia Médica. 2004;35:12-7.

21. República de Colombia. Ministerio de Salud. Por la cual se establecen las normas científicas, técnicas y administrativas para la investigación en salud Resolución No 008430 de octubre 4 de 1993. Bogotá: Ministerio de Salud; 1993.

22. Sambrook J, Fritzch EF, Maniatis T. Molecular cloning. A laboratory manual. New York: Ed. Cold Spring Harbor Press; 1989.

23. Seiki M, Hattori S, Hirayama Y, Yoshida M. Human adult T-cell leukemia virus: complete nucleotide sequence of the provirus genome integrated in leukemia cell DNA. Proc Natl Acad Sci USA. 1983;80:3618-22.

24. Feinberg AP, Vogelstein B. Technique for radiolabeling of restriction endonuclease fragments. Anal Biochem. 1983;132:6-13.

25. Miyoshi I, Kubonishi I, Yoshimoto S, Akagi T, Ohtsuki Y, Shiraishi Y, et al. Type $\mathrm{C}$ virus particles in a cord T-cell line derived by co-cultivating normal human cord leukocytes and human leukaemic T cells. Nature.1981;294:770-1.

26. Takemoto S, Matsuoka M, Yamaguchi K, Takatsuki $\mathrm{K}$. A novel diagnostic method of adult T-cell leukemia: Monoclonal integration of human T-cell lymphotropic virus type I provirus DNA detected by inverse polymerase chain reaction. Blood. 1994;84:3080-5.

27. Cavrois M, Gessain A, Wain-Hobson S, Wattel E. Proliferation of HTLV-I infected circulating cells in vivo in all asymptomatic carries and patients with TSP/HAM. Oncogen. 1996;12:2419-23.

28. Cabrera J, García-Vallejo F. Aumento del número de amplicones obtenidos por IPCR en el ADN de personas seropositivas para HTLV-I afectadas con PET/HAM. Colombia Médica. 2000;31:169-75.

29. Ozawa T, Itoyama T, Sadamori N, Yamada Y, Hata T, Tomonaga M, et al. Rapid isolation of viral integration site reveals frequent integration of HTLV-1 into expressed loci. J Hum Genet. 2004;49:154-29.

30. STATA CORP. Stata Statistical Software: Release 8.0 College Station TX: Stata Corporative; 2000.

31. Venter JC, Adams MD, Myers EW, Li PW, Mural RJ, Sutton GG, et al. The sequence of the human genome. Science. 2001;291:1304-51.

32. International Human Genome Sequencing Consortium. Initial sequencing and analysis of the human genome. Nature. 2001;409:860-921.

33. Blank A. Adult T-cell leukemia/lymphoma in southwest Colombia. En: HTLV, truths and questions. Cali: Edit Zaninovic; 1996. p. 266-71.

34. Wattel E, Vartanian JP, Pannetier $\mathrm{CH}$, Wain-Hobson S. Clonal expansión of human T-cell leukemia and symptomatic carries without malignancy. J. Virol. 1995;69:2863-8.

35. Wattel E, Cavrois, Gessain MA, Wain-Hobson S. Clonal expansion of infected cells -a way of life for HTLV-I. J Acquir Immune Defic Syndr Hum Retrovirol. 1996;13(Supl.1):92-9.

36. Doi K, Wu X, Taniguchi Y, Yasunaga J, Satou Y, Okayama A, et al. Preferential selection of human T-cel leukemia virus type I provirus integration sites in leukemic versus carrier status. Blood. 2005;106:1048-53.

37. Hanai S, Nitta T, Shoda M, Tanaka M, Iso N, Mizoguchi I, et al. Integration of human T-cell leukemia virus type 1 in genes of leukemia cells of patients with adult T-cell leukemia. Cancer Sci. 2004;95:306-10.

38. Spence JM, Mills W, Mann K, Huxley C, Farr CJ. Increased missegregation and chromosome loss with decreasing chromosome size in vertebrate cells. Chromosoma. 2006;115:60-74.

39. Leclercq I, Mortreux F, Cavrois M, Leroy A, Gessain A, Wain-Hobson $\mathbf{S}$, et al. Host sequences flanking the human T-cell leukemia virus type 1 provirus in vivo. J Virol. 2000;74:2305-12.

40. Oliver JL, Carpena P, Román-Rolatán R, MataBalaguer $\mathrm{T}$, Mejias-Romero A, Hackenberg M, et al. Isochore chromosome maps of the human genome. Gene. 2002;300:117-27.

41. Lengauer C, Kinzler KW, Vogelstein B. Genetic instabilities in human cancers. Nature. 1998 396:643-9. 
42. Pavlícek A, Jabbari K, Paces J, Paces V, Hejnar J, Bernardi G. Similar integration but different stability of Alus and LINEs in the human genome. Gene. 2001;276:39-45.

43. Tsuji T, Sugahara $K$, Tsuruda $K$, Uemura A, Harasawa $\mathrm{H}$, Hasegawa $\mathrm{H}$, et al. Clinical and oncologic implications in epigenetic down-regulation of CD26/dipeptidyl peptidase IV in adult T-cell leukemia cells. Int J Hematol. 2004;80:254-60.

44. Derce D, Crise B, Li Y, Princler G, Lum N, Stewart C, et al. Human T-cell leukemia virus type 1 integration target sites in the human genome: comparison with those of other retroviruses. J Virol. 2007;81:6731-41.

45. Agbottah E, Deng L, Dannenberg LO, Pumfery A, Kashanchi F. Effect of SWI/SNF chromatin remodeling complex on HIV-1 Tat activated transcription. Retrovirology. 2006;3:48-67.

46. Mitchell RS, Beitzel BF, Schroder AR, Shinn P, Chen $\mathrm{H}$, Berry CC, et al. Retroviral DNA integration: ASLV, HIV, and MLV show distinct target site preferences. PLoS Biol. 2004;2:1127-37.

47. Wu X, Burgess S M. Integration target site selection for retroviruses and transposable elements. Cell Mol Life Sci. 2004;61:2588-96.

48. Versteeg R, van Schaik BD, van Batenburg MF, Roos M, Monajemi R, Caron H, et al. The human transcriptome map reveals extremes in gene density, intron length, GC content, and repeat pattern for domains of highly and weakly wxpressed genes. Genome Res. 2003;13:19982004. 